ISSN 1112-9867

\title{
EVALUATION AND RELIABILITY OF BONE HISTOLOGICAL AGE ESTIMATION METHODS
}

\author{
I. Khan ${ }^{1}$, M. M. A. Jamil ${ }^{1, *}$ and F. M. Nor ${ }^{2}$ \\ ${ }^{1}$ Faculty of Electrical and Electronic Engineering, UniversitiTun Hussein Onn Malaysia, \\ BatuPahat, Johor, Malaysia \\ ${ }^{2}$ Department of Pathology, Faculty of Medicine, UniversitiKebangsaan Malaysia, Medical \\ Centre, Kuala Lumpur, Malaysia
}

Published online: 05 October 2017

\begin{abstract}
Human age estimation at death plays a vital role in forensic anthropology and bioarchaeology. Researchers used morphological and histological methods to estimate human age from their skeletal remains. This paper discussed different histological methods that used human long bones and ribs to determine age estimations. The applicability of those methods, commonly quantified variables, sample size, sampling method and their accuracy are discussed as well. The review of those methods showed that the nature of research for estimating age at death has been shifted from gross morphological analysis to histological analysis, and its further going towards the use of digital image processing tools to achieve high accuracy. Histological methods based on the analysis of bone cross-sections showed that there is a strong correlation between increasing age and bone microstructures. Frequently analyzed bone microstructures are osteon and haversian canal and their derivatives. Even though researchers have achieved a satisfactory level of accuracy in young individuals, yet the estimating of age in older individuals is the challenging part.
\end{abstract}

Author Correspondence, e-mail: drmuhammadmahadi@gmail.com

doi: http://dx.doi.org/10.4314/jfas.v9i4s.38 
It is expected that the ongoing research and future studies will find its way to achieve high level of accuracy in both young and older individuals.

Keywords: human; bones; microstructures; digital images; age; forensic; osteoarchaeology.

\section{INTRODUCTION}

Estimation of human age at death using anatomical information from their skeletal remains consists of estimation of physiological age and correlating it to chronological age. The accuracy of the developed techniques for estimating human age at death, varies with the availability and nature of the samples and age of individuals [1-2]. Accurate age estimation techniques are important in forensic field, developing demographic profile and individual analysis of human remains. According to [3], age estimation techniques are important to narrow the search possibilities, while examining unknown victims to determine the age at death when unknown and to differentiate the victims of mass grave.

Initial techniques for estimating age at death were based on macroscopic, morphological analyses of bone [4-8]. These macroscopic methods were qualitative and were dependent on subjective assessment of various degeneration stages. Macroscopic approaches are nondestructive and can be performed quickly, however qualitative analysis in macroscopic approaches leads to a significant amount of observer error. Also, the skeletal remains often encountered in forensic science are highly fragmented or burnt that alters the morphology of the bones to the extent where gross morphological methods are no longer useful. To overcome these limitations, researchers adopted quantitative and objective histological methods for age estimation which were based on bone microstructures that are proven useful and provided major benefits. Much research has been done on developing methods to estimate human age at death from various elements of skeletal remains such as teeth, pelvis, ribs and long bones (humerus, radius, tibia, ulna, fibula and femur) [9-12].

This paper will give an overview of age estimation techniques from human long bones (humerus, radius, tibia, ulna, fibula and femur) and ribs. General reviews for estimating age at death based on different parts of body have been discussed and published by [13-21]. This paper will focus on discussion of critical evaluation of histological and histomorphometric methods for age estimation, their applicability, commonly quantified variables, sample size, sampling method and their accuracy. 


\section{AGE ESTIMATION TECHNIQUES}

Jowsey in 1960 used microradiographs of femoral cross-section to analyze age-related changes in bone microstructures, and had noticed considerable variations in bone structure [22]. Jowsey analyzed the formation and resorption of bone in microradiographs, and reported that there was a high amount of bone formation and resorption in young individuals that lead to high rate of bone turn over and high degree of porosity. The researcher reported that there was a lower rate of turnover in young adults, while high rate of resorption in older adults. Jowsey reported that there was little evidence of increase in bone formation in individuals over 70 years of age, and up to $25 \%$ of their endosteal bone surface may be occupied by resorption. In individuals over 60 years, Jowsey noticed an increase in osteon numbers that are less than $75 \%$ closed. Jowsey stated that the porosity and variation of bone density was high in individuals over 60 years.

Kerley in 1965 used histomorphometric method to estimate human age from femur, tibia and fibula [9]. 115 European American and 11 African American samples were analyzed of which 88 were males and 29 were females, and 9 were individuals of unknown sex. The samples covered the age range from birth through 95 years old. Four circular fields in femoral midshaft for analysis located anteriorly, posteriorly, medially and laterally were chosen shown in Fig. 1.

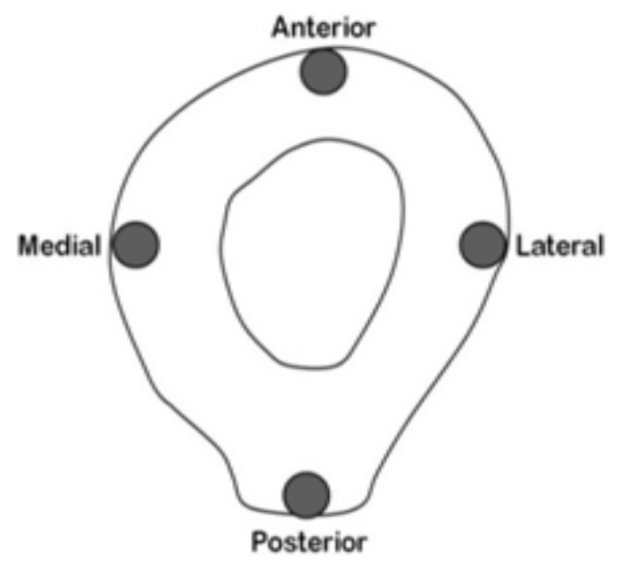

Fig.1. Cross-section of femoral midshaft demonstrating the location of Kerley's four fields of analysis [9]

Each of the four fields was $1.25 \mathrm{~mm}$ in diameter. Kerley analyzed absolute counts of intact osteon, osteon fragment, percentage of circumferential lamellar bone and number of non-haversian canal. Kerley developed separate regression equation for variables of tibia, fibula and femur, as shown in Table 1. It was reported that sex and ancestry did not have observable effects on bone microstructures. Kerley's results showed that with increasing age, 
osteon numbers and osteon fragments numbers increases while percentage of circumferential lamella and number of non-haversian canals decreases.

In [23] attempted to improve Kerley's method. They analyze femoral cross section of 20 specimens of known age and rotated the location of Kerley's sampling field in a way that each observing field was positioned between Kerley's four chosen field locations. They reported that the definitions of variables provided by Kerley's were uncertain that caused an increase in observational error and affect the reliability of results. Considering Kerley's definitions of variables, in [23] found it difficult to differentiate between complete osteons and fragmented osteons. To find the percentage of remodeled bone in chosen fields, they used an eyepiece reticule.

However, in [24] reported that considering some portion of samples from which the original method is derived is not sufficient to test the reliability of the method. They calculated the average of Kerley's regression equations estimates and derived more reliable age estimates. In 1977, in [25] reported that the field size chosen by Kerley should be larger than $1.25 \mathrm{~mm}$. In [10] corrected the original method by increasing microscopic filed size from $1.25 \mathrm{~mm}$ to 1.62 $\mathrm{mm}[10]$. They introduced a correction factor, and reported that count of osteon, fragmented osteon and non-haversian canal should be multiplied by this correction factor. However, estimated percent of lamellar bone should not be multiplied with correction factor.

Table 1.Kerley's regression equations for estimating age $(\mathrm{Y})$ from factor value $(\mathrm{X})$

\begin{tabular}{ccc}
\hline Factor & Regression Equation & Standard Error \\
\hline Femoral osteons & $\mathrm{Y}=3.473+0.144 \mathrm{X}+0.003 \mathrm{X}_{2}$ & 9.39 \\
Femoral fragments & $\mathrm{Y}=8.786+0.834 \mathrm{X}$ & 12.19 \\
Femoral lamellar & $\mathrm{Y}=79.455-2.427 \mathrm{X}+0.023 \mathrm{X}_{2}$ & 11.78 \\
Femoral non-haversian & $\mathrm{Y}=57.811-1.782 \mathrm{X}+0.013 \mathrm{X}_{2}$ & 13.85 \\
Tibial osteons & $\mathrm{Y}=-10.082+0.634 \mathrm{X}$ & 6.69 \\
Tibial fragments & $\mathrm{Y}=-7.061+0.931 \mathrm{X}+2.210 \mathrm{X}_{2}-2.538 \mathrm{X}_{3}$ & 7.78 \\
Tibial lamellar & $\mathrm{Y}=76.388-1.794 \mathrm{X}+0.011 \mathrm{X}_{2}$ & 13.62 \\
Tibialnon-haversian & $\mathrm{Y}=70.270-10.944 \mathrm{X}+0.6470 \mathrm{X}_{2}-0.011 \mathrm{X}_{3}$ & 9.63 \\
Fibular osteons & $\mathrm{Y}=2.366-0.538 \mathrm{X}+0.018 \mathrm{X}_{2}-0.001 \mathrm{X}_{3}$ & 8.83 \\
Fibular fragments & $\mathrm{Y}=1.328-0.058 \mathrm{X}+0.034 \mathrm{X}_{2}$ & 5.27 \\
Fibular lamellar & $\mathrm{Y}=69.108-2.208 \mathrm{X}+0.015 \mathrm{X}_{2}$ & 10.85 \\
Fibular non-haversian & $\mathrm{Y}=55.241-4.300 \mathrm{X}+0.050 \mathrm{X}_{2}$ & 10.70 \\
\hline
\end{tabular}


In [26] conducted a study to quantitate age-related changes in bone microstructures. They analyzed 59 specimens of which 52 were males, covering the age range from 39 to 87 . The samples were taken from mandible, femur and tibia to analyze three factors such as (1) osteons number (2) average number of lamellae per-osteon (3) average haversian canal diameter. They used multiple regression techniques to find out that osteon number per unit area of bone and number of lamella per osteon increased with increasing age, while haversian canal diameter decreased with age. They also stated that haversian canal diameter and osteon number have the highest correlation with age, while number of lamella per osteon has the least significant relation with age. They also reported that the potential error introduced by osteon fragment counting could be reduced by considering osteon count only. Their study also contradicted an earlier study by [27], which reported little correlation between haversian canal size and increasing age. However, problems with [28] were that they selected random microscopic field without any specific location. They did not provide much information about sex and ancestry effects on bone microstructures. Their proposed changes to Kerley's method could not improve the accuracy of Kerley's method.

In [29] proposed a histological method using $0.4 \mathrm{~cm}$ diameter core of cortical bones to estimate human age beyond 50 years. He analyzed microstructures of femur, tibia, humerus and ulna of 116 samples of which 64 were males and 52 were females covering the age range of 30 to 97 . Thompson used point-count method with 10x10 grid eyepiece in four fields of anterior posterior region. The percentage of osteonal area was calculated by summing up haversian canal area and secondary osteon lamellae. Thompson stated that the percentage of osteonal area is the best predictor of age estimation. Later, in [30] developed sex-specific equation, and reported that females experienced additional 10 years of bone loss compared to men. In [31] reported that in white population, femur samples produce the most accurate age estimation. However, during the 80 's, there were no standard rules for accurate age estimation, a problem that still exist today [32].

In [33] attempted to estimate human age from middle third portion of the sixth rib in order to reduce sampling error caused by field location and lack of samples availability. Stout reported that by sampling the entire cross-section, one can apply this method to fragmentary ribs as well. Stout studied cortical area, mean osteonal cross-sectional area, ratio of cortical area to total cross-sectional area, number of intact osteons, fragmentary osteon density, intact osteon density, total visible osteon creations, mean annual osteon creation frequency, effective age of adult compacta and mean annual Haversian bone formation rate. Less information about developing regression equation for age estimation were given. He claimed that his method can 
be used to investigate age from human ribs and was used in a case report of Francisco Pizzarro[32].

In [34] developed a histological method for age estimation using fragmented and weathered bones samples. They reported that haversian canal parameter was easy to identify in poorly preserved bones. They analyzed haversian canal number and diameter in 58 samples of individuals. They reported that their method was more reliable for males, but less reliable for females due to the effects of hormonal level variations on remodeling during pregnancy and menopause. In their method, they did not consider osteon fragment having no visible canal which could lead to leaving out the evidence of activation. Ignoring such osteon fragment can affect accuracy of the method when applied to older individuals that have high proportion of fragments.

In [35] analyzed $1.0 \mathrm{~cm}$ wide anterior wedge from femoral mid-shaft taken from 328 specimens, of which 174 were males and 154 females. The age range of specimen covered was from 14 years to 97 years old. Ericksen did not exclude the specimen with pathological conditions so the method could be widely applicable for individual with unknown history. $\mathrm{He}$ located and photographed five $0.886 \mathrm{~mm}^{2}$ fields at the periosteal edge to define the fields and provided a permanent record. Ericksen documented osteon $/ \mathrm{mm}^{2}\left(\mathrm{X}_{1}\right)$, type II osteons $/ \mathrm{mm}^{2}$ $\left(\mathrm{X}_{2}\right)$, fragments $/ \mathrm{mm}^{2}\left(\mathrm{X}_{3}\right)$, resorption spaces $/ \mathrm{mm}^{2}\left(\mathrm{X}_{4}\right)$ secondary osteons, non-haversian canals $/ \mathrm{mm}^{2}\left(\mathrm{X}_{5}\right)$ and used 100 spaces grid to measure average percent of (unremodeled bone $\left(\mathrm{X}_{6}\right)$, osteonal bone $\left(\mathrm{X}_{7}\right)$ and fragmental bone $\left(\mathrm{X}_{8}\right)$. Regression equations for males, females and combined sex using stepwise regression were produced. 
Table 2.Regression equations of combined sexes [35]

\begin{tabular}{cc}
\hline Regression Equation for Combined Sexes & SEE \\
\hline $\mathrm{Y}=75.49-0.53 \mathrm{X}_{6}$ & 12.21 \\
$\mathrm{Y}=60.45+0.47 \mathrm{X}_{3}-0.32 \mathrm{X}_{6}$ & 11.20 \\
$\mathrm{Y}=53.12+0.60 \mathrm{X}_{3}-2.67 \mathrm{X}_{5}$ & 10.66 \\
$\mathrm{Y}=44.06+0.68 \mathrm{X}_{1}+0.60 \mathrm{X}_{3}-2.05 \mathrm{X}_{5}$ & 10.43 \\
$\mathrm{Y}=43.4+0.61 \mathrm{X}_{1}+2.01 \mathrm{X}_{2}+0.52 \mathrm{X}_{3}-1.97 \mathrm{X}_{5}$ & 10.25 \\
$\mathrm{Y}=38.11+0.80 \mathrm{X}_{1}+2.22 \mathrm{X}_{2}+0.31 \mathrm{X}_{3}-1.54 \mathrm{X}_{5}+0.23 \mathrm{X}_{8}$ & 10.17 \\
$\mathrm{Y}=40.77+1.02 \mathrm{X}_{1}+2.34 \mathrm{X}_{2}+0.24 \mathrm{X}_{3}-1.76 \mathrm{X}_{5}-\mathrm{O}_{11} \mathrm{X}_{7}+0.26 \mathrm{X}_{8}$ & 10.15 \\
$\mathrm{Y}=67.43+1.11 \mathrm{X}_{1}+2.46 \mathrm{X}_{2}+0.20 \mathrm{X}_{3}-1.57 \mathrm{X}_{5}-0.30 \mathrm{X}_{6}-0.39 \mathrm{X}_{7}$ & 10.08 \\
$\mathrm{Y}=94.98+\mathrm{I}_{1} 10 \mathrm{X}_{1}+2.48 \mathrm{X}_{2}+0.24 \mathrm{X}_{3}-\mathrm{I}_{1} .50 \mathrm{X}_{5}-0.58 \mathrm{X}_{6}-0.65 \mathrm{X}_{7}-0.34 \mathrm{X}_{8}$ & 10.07 \\
$\mathrm{Y}=92.42+1.07 \mathrm{X}_{1}+2.50 \mathrm{X}_{2}+0.26 \mathrm{X}_{3}+\mathrm{O} .30 \mathrm{X}_{4}-1.52 \mathrm{X}_{5}-0.57 \mathrm{X}_{6}-0.61 \mathrm{X}_{7}-0.35 \mathrm{X}_{8}$ & 10.08
\end{tabular}

The standard error of estimates (SEE) in Erickson's method was about +/- 10 years. He reported that sex-specific equations had higher accuracy than opposite-sex or non-specific equations. The reason for this high accuracy was due to different pattern of relation between osteons and osteon fragments with increasing age in males and females.

In [36] revised their earlier method of [33] by including 40 samples of clavicle and ribs. They developed a histological method and tested it on 83 other samples in 1996 from Swiss cemetery and reported that this method can reasonably estimate age from ribs and clavicle, but the accuracy was low for samples over the age of 40 years. They also reported that age estimation methods based on osteon population density were not reliable from bones that have reached asymptote, as the predicted age will vary from bone to bone even for the same individual. They also reported that osteon population difference exhibited no significant difference between males or females for those samples.

In [37] attempted to compare the accuracy of microscopic and macroscopic method, particularly Kerley's histological method. They analyzed 20 samples from Spitalfields' skeletal collection. They reported that Kerley's microscopic method is reliably accurate for Spitalfields' skeletal collection, but not as accurate as [8] pubic symphysis technique. They further reported that the three age estimation methods from pubic symphysis morphology are partially dependent on the age structure of the population, upon which they were developed. They suggested that the combination of pubic symphysis and histological approach could produce better results for estimating age. However, the problem with their analysis was that 
the known ages of their samples were based on church records which did not necessarily provide the reliability of exact accurate known age. Furthermore, to check the accuracy of Kerley's method, they did not use the location and definitions used by Kerley. Besides, in [37] also used anterior thin section wedges, unlike Kerley, who used complete cross-section of femur.

In [38] had developed a histological method using 40 samples of Japanese population covering the age from 23 years to 80 years old. They used thin section of humerus, and collected ten histological variables. Following Erickson's method, they applied linear and stepwise regression analysis to their samples. Their results reported a low absolute mean difference between the estimated and known age.However, they did not test the accuracy of their method on independent sample, but cross-validated on a subsample of eleven individuals, which were derived from the original sample to establish the technique.

In [39] used femoral midshaft of 195 samples covering the age range from 1 to 97 years old of Australian population [39]. The samples were reported to have no pathological conditions. They adjusted 3 groups of sectional ages (19-21 years, 39-41years, 59-61 years, $n=9$ for each group) to a thickness of $100+/-5 \mu \mathrm{m}$ by hand lapping. Using microradiograph, automated image analysis method was applied to measure the perimeter and area of femoral cortex. Furthermore, they measured the number and area of holes within femoral cortex. They reported that there was no significant change in the increasing rate of periosteal parameter between males and females from age 20-97 years. However, male bone samples have significantly larger perimeters at all ages. They also grouped their samples in decades and applied t-tests in both sex samples for mean perimeters comparison, and reported that it was significantly larger $(\mathrm{p}<0.05)$ in males compared to females in all decades except the first and tenth decade. They reported that haversian canal have a correlation with increasing age.However, the spread of values at any given age made these measurements of less use in age estimation which in turn made the methods based on haversian canal measurements flawed to some extent.

In [40] studied anterior portion of femur samples. They selected three fields in mid-cortical region, each having area of $0.7 \mathrm{~mm}^{2}$. Their study was based on 98 Japanese samples (72 males, 26 females). The age range of these individuals was from 43 days to 88 years. Selected bone microstructures for analysis were osteons, haversian canals, diameter and perimeter of osteon and haversian canals, number of osteon fragments and type II osteons and the area of the triangles, formed by connecting the center of three haversian canals. They reported that perimeters of osteons had a high correlation with increasing age than haversian canals. The 
standard error of their method was between 3.16 and 11.50 years. They presented a hypothesis that staining the bone with Villanueva's powder and thionic dye makes it easy to distinguish between bone microstructures, thus providing more accuracy.

In [41] studied 96 samples of femoral mid-diaphysis covering age range from 21 to 92 years. They developed age estimation equations based on both macroscopic and microscopic data. Macroscopic data involved total subperiosteal area, periosteal perimeter, endosteal perimeter and cortical bone area. Microscopic data involved number, size and diversities of pores and intercortical porosity. They reported that total subperiosteal area and periosteal perimeter were independent predictor of age, but the microscopic feature i.e. number of pores had no significant correlation with age. They reported that age predicted by their equations was inaccurate for half of samples having age above than 8 years. They concluded that automated bone measurements according to cortical region along with total subperiosteal area and periosteal perimeter could be more useful for age estimation.

In [42] analyzed 66 samples over 21 years of age to identify whether remodeling osteons in femoral shaft were clustered and to assess the influence of age and sex. They took microradiographs of femoral mid-shaft cross section and analyzed the number, size and location of haversian canals. They used edge detection algorithm and cluster analysis to identify recently remodeled osteons within $0.75 \mathrm{~mm}$ clusters. They reported that in femoral neck, remodeling osteons were significantly more clustered but the density of these clusters was not significantly associated with age or gender. They also reported that the density of remodeling osteons was greater near the periosteum and decreased towards the marrow cavity. They also noted that cortical porosity has an increasing relation with age and suggested that remodeling osteons in the shaft and neck of the femur were independent of age.

In [43] studied 154 bone samples in order to modify [33, 36] methods. Of 154 samples, 103 were African-American and 51 were European-American. The European-American sample included 36 samples of original Stout and Paine's method samples. They divided the samples into two sets, developmental set and validation set. The developmental set comprised 103 samples (69 African-American, 34 European-American), while the validation set comprised 51 samples (34 African-American, 17 European-American). They analyzed the measurements, which were used in Stout's original method, and also included mean osteonal cross-sectional area to the analysis. They noted that osteon population density changes with ancestry and osteon size is smaller in African-American than European-American. Their validation test produced similar results with their original method. 
In [44] investigated the pattern of porosity distribution in the midshaft of femoral bones. The samples comprised 168 individuals of Australian population, of which 73 were females and 95 were males. The age range of the individuals was between 20 to 97 years. They took microradiographs of $100 \mu \mathrm{m}$ sections, and used image processing tools to detect pore and bone areas. They reported that analysis of ratio of medullar area to total subperiosteal area produce clear results. They divided the cortex into three radial rings and eight circumferential parts as shown in Fig. 2.

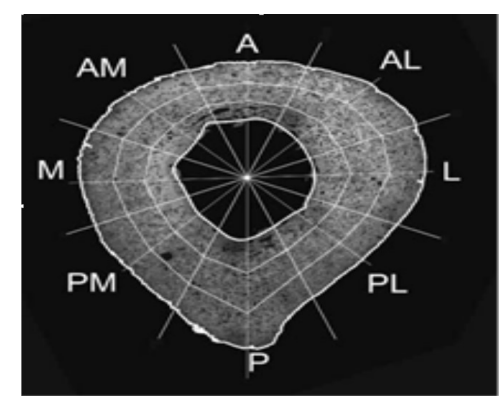

Fig.2. Cortex subdivision A (anterior), AL (anterolateral), L (lateral), PL (posterolateral), P (posterior), PM (posteromedial), M (medial), AM (anteromedial), Three rings (periosteal, midcortical and endosteal) [44]

They calculated the porosity in each segment and reported that porosity increased in the inner part of the cortex with increasing age and the pattern of porosity was consistent with continuous bone loss in neutral axis of cortex.

In [45] investigated 162 Western European samples to analyze wedge- shaped segments of the femur midshaft along the anterior portion. Sample collection comprised 86 males and 76 females covering the age range of 15 to 96 years. They studied $1 \mathrm{~mm}^{2}$ section of cortical area, and computed the percentage of non-remodeled circumferential lamella along the periosteal surface of the bone. They reported that there was no significant difference in the percentage of unremodeled bone between males and females.

In [46] attempted to develop a histological method based on intra- and intersectional variation that occurs in the femoral cortex to find out the extent of regional variation within the femur. They quantified the ratio of the secondary osteon lamella and haversian canal and measured cortical thickness. They used Thompson's all males left femur regression equation, but at the same time they attempted to apply this equation for locations taken from different femoral diaphysis to compare to locations used in Thompson's method. They reported that the posterior location within the femoral cortex exhibited more variability than anterior location used in Thompson's method. They concluded that Thompson's method can be applied to any location along the anterior femoral midshaft. They also reported that histological variation 
that exists between anterior location and other three locations (i.e. posterior, lateral and medial) may give rise to age estimates, which was a deviation from the Thompson's age estimates from anterior midshaft.

In [47] investigated the microradiographs of 88 samples of femoral mid diaphyseal specimen in order to find out the link between osteon geometry with weight, age and sex. They hypothesized that osteon size i.e. area and diameter are inversely proportional to weight if age, sex and height are controlled. Their investigation was based on univariate analysis of covariance in which sex was kept as a fixed factor and height, age and weight were conducted as covariance. They concluded that weight was negatively proportional to osteon area and osteon diameter, while age had a correlation with osteon circularity. They also reported that osteon area and diameter varied between females and males with males having larger osteons. However, they did not find any correlation between sex and osteon circularity. They noticed that height had no correlation at all with osteon geometry.

In [48] investigated 50 samples of Malaysian males covering age range from 21 to 78 years. In this research, ten microstructural parameters in the mid-diaphyseal cortex of upper and lower long limb bones (humerus, ulna, radius, femur, tibia and fibula) were analyzed. The microstructural parameters included osteon (count, diameter, area and perimeter), haversian canal (diameter, area and perimeter), lamella count, cortical thickness, medullary cavity diameter. Four subperiosteal locations were chosen for microstructural analysis namelyanteromedial, anterolateral, posteromedial and posterolateral. The researcher tested the correlations between microstructures and age using the Pearson's correlation and used multivariate regression analysis for developing age regression equations. In [48] reported that osteon size decreased with age, while haversian canal area, diameter and perimeter have positive correlations with increasing age. It was also reported that the number of haversian canal decreased with age and osteon size were smaller due to the shrinking of overall size of haversian system with increasing age. It was noticed that medullary cavity diameter has a negative correlation with age. This method showed the accuracy of age estimation within 10.94 years of the true value.

Table 3 showed different regression equations along with standard error of estimates (SEE) developed by researchers using different bone samples. 
Table 3.Regression equations for age estimation using bone microstructures

\begin{tabular}{ccc}
\hline References & Regression Equation & SEE (Years) \\
\hline$[9]$ & $57.811-1.728(\mathrm{NH})+0.013(\mathrm{NH})^{2}$ & 13.85 \\
{$[26]$} & $89.01-0.62(\mathrm{HCD})$ & 3.82 \\
{$[29]$} & $28.978+128.557(\mathrm{HLC}+\mathrm{HCA})-1.79(\mathrm{CT})-7.543$ & 7.06 \\
& $(\mathrm{OP} / \mathrm{OC})-7.633($ Total OP) $+2.688(\mathrm{OC})$ & \\
{$[35]$} & $92.42+1.07(\mathrm{OC})+2.5($ type II Osteon)+0.25 (F)+0.3 & 10.08 \\
{$[33]$} & $(\mathrm{RS})-1.52(\mathrm{PC})-0.57(\mathrm{Mpub})-0.61(\mathrm{Mpob})-0.35(\mathrm{Mpfb})$ & \\
{$[38]$} & $-12.239+2.873($ total osteon count) & \\
{$[48]$} & $5.72+2.89(\mathrm{OC})$ & 9.28 \\
{$[48]$} & $5.57-1.47(\mathrm{HCD})+0.23(\mathrm{HCA})-1.30(\mathrm{MCD})-0.36(\mathrm{OD})$ & 9.71 \\
& $5.484+1.19(\mathrm{OC})-0.282(\mathrm{OD})+0.706(\mathrm{HCD})$ & 12.62 \\
\hline
\end{tabular}

whereNH: non-haversian, HCD: haversian canal diameter, HLC: haversian lamella count, HCA: haversian canal area, CT: cortical thickness, OP: osteon population, OC: osteon count, F: fragments, RS: resorption spaces, PC: primary canal, Mpub: Mean percent unremodeled bone, Mpob: mean percent osteonal bone, Mpfb: mean percent fragmental bone and MCD: medullar cavity diameter, OD: osteon density.

\section{RESULTS AND DISCUSSION}

Several methods have been developed to estimate human age at death from their skeletal remains. Initially these methods were based on morphological analysis of bone. However, due to the fragmentary nature of skeletal remains, researchers have adopted histological analyses for age estimation. The advantage of morphological analysis lies in its non-destructive nature. However, its applicability is limited in cases, where only fragments of bones are found. Histological methods, on the contrary can be used to estimate human age at death even from bone fragments. Histological methods have been applied to different parts of body considering the availability of bones. Studies based on femoral bones have produced better results for age estimation. Different researchers used various bone microstructures in their analysis including osteons, haversian canals, lamella count, secondary osteons, etc. It was found that osteon and haversian canal possess strong correlation with age. Many researchers reported that osteon number and haversian canal area increases with maturity of bones. It is also noticed that ancestry, race and region may affect the nature of the bone microstructures. 
In some studies, gender is also considered to have significant effect on bone microstructures[49]. These variations led researchers to develop different regression equations for different populations. The accuracy of each method varies based on their analysis and availability and nature of samples.

The common drawback in all the aforementioned techniques was its manual data collection, as manual measurements of bone microstructures is more vulnerable to human error. To overcome such issues, this research proposes the transformation of manual measurements of microstructures into automatic extraction and measurements with the help of digital image processing tools. The specimen preparation and selection of location for bone images has been explained in [50-51]. This study aims to use image preprocessing steps to extract bone microstructures from digital images automatically. These steps involves noise and distortion reduction, enhancing, magnifying, and smoothing of image. Various clustering methods e.g. adaptive noise filtering algorithm, pixel intensity level algorithm along with thresholding and object identification can be used to distinguish between different bone microstructures. After the extraction of bone microstructures, various classification techniques can be tested to classify human age into groups based on the characteristics of the bone microstructures.

\section{CONCLUSION}

Although, there is no standard set for regression equation so far, yet many researchers reported that their methods are more reliable for young individuals and less reliable for older individuals. The accuracy of the age estimation techniques could be improved by the introduction of computer aided systems and faster algorithms. As the nature of microscopic images of bone microstructures play a vital role in estimating age at death, it is important to introduce the latest image processing tools and software to achieve higher accuracy which is the future work of our research. Our research focuses on the use of image processing tools in order to automate the process of human age estimation. Automating this process will have several benefits e.g. It will allow the gathering and storage of enormous amount of data. It is also expected to increase the accuracy of the extracted microstructures from digital images as manual measurements on a large cross-sectional area is demanding. It is also expected to reduce the chance of the introduction of subjective bias and human error. The results of our research will be published in the next paper. 


\section{ACKNOWLEDGEMENTS}

The authors would like to express their gratitude to the UniversitiTun Hussein Onn Malaysia (UTHM) and the Centre for Graduate Studies (CGS) that provided the financial support.

\section{REFERENCES}

[1] Kerley E R. Forensic anthropology and crimes involving children. Journal of Forensic Science, 1976, 21(2):333-339

[2] S S Katzenberg M A, Ubelaker DH. Methodological considerations in the forensic applications of human skeletal biology. InM. A.Katzenberg, \& S. R.Saunders (Eds.), Biological anthropology of the human skeleton.New York: Wiley-Liss, 2000, pp. 41-67

[3] Lewis J M, Senn D R. Dental age estimation utilizing third molar development: A review of principles, methods, and population studies used in the United States. Forensic Science International, 2010, 201(1):79-83

[4] Krogman W M. Skeletal changes in young American males. American Journal of Orthodontics, 1958, 44(9):715-716

[5] Todd T W. Age changes in the pubic symphysis: VII. The anthropoid strain in human pubic symphyses of the third decade. Journal of Anatomy, 1923, 57(Pt 3):274-294

[6] Todd T W. Age changes in the pubic bone. I. The male white pubis. American Journal of Physical Anthropology, 1920, 3(3):285-334

[7] Brooks S T. Skeletal age at death: The reliability of cranial and pubic age indicators. American Journal of Physical Anthropology, 1955, 13(4):567-597

[8] Acsádi G, Nemeskéri J. History of human life span and mortality. Current Anthropology, $1974,15(4): 300-302$

[9] Kerley E R. The microscopic determination of age in human bone. American Journal of Physical Anthropology, 1965, 23(2):149-163

[10]Kerley E R, Ubelaker D H. Revisions in the microscopic method of estimating age at death in human cortical bone. American Journal of Physical Anthropology, 1978, 49(4):545-546

[11] Wakely J. Death, decay and reconstruction-Approaches to archaeology and forensic science. Journal of Anatomy. 1988, 160:233 
[12]Khan I, Nor F M, Jamil M A. A survey of human age estimation techniques from bone microstructures. In International Conference for Innovation in Biomedical Engineering and Life Sciences, 2015, pp. 203-207

[13] Bass W M. Human osteology: A laboratory and field manual. Missouri Archaeological Society, 1997

[14]Iscan M. Y., Steyn M. The human skeleton in forensic medicine. Illinois: Charles C Thomas Publisher, 2013

[15]Cunningham C., Scheuer L., Black S. Developmental juvenile osteology. Massachusetts: Academic Press, 2016

[16]Katzenberg M A. The anatomy and biology of the human skeleton. Human Biology, 1990, 62(4):582-584

[17] Stewart T. D. Essentials of forensic anthropology: Especially as developed in the United States. Illinois: Charles C. Thomas Publisher, 1979

[18]Sundick R I. Age and sex determination of subadult skeletons. Journal of Forensic Science, 1977, 22(1):141-144

[19]Ubelaker D. H. Human skeletal remains: Excavation, analysis, interpretation. Washington DC: Taraxacum, 1984

[20] White T. D., Black M. T., Folkens P. A. Human osteology. New York: Academic Press Inc., 2011

[21]Ferembach D, Schwindezky I, Stoukal M. Recommendation for age and sex diagnoses of skeletons. Journal of Human Evolution, 1980, 9:517-549

[22]Jowsey J. Age changes in human bone. Clinical Orthopaedics, 1960, 17:210-218

[23] Ahlqvist J, Damsten O. A modification of Kerley's method for the microscopic determination of age in human bone. Journal of Forensic Sciences, 1969, 14(2):205-212

[24] Stout SD, Gehlert SJ. The relative accuracy and reliability of histological aging methods. Forensic Science International, 1980, 15(3):181-190

[25] Bouvier M, Ubelaker DH. A comparison of two methods for the microscopic determination of age at death. American Journal of Physical Anthropology, 1977, 46(3):391-394 
[26] Singh IJ, Gunberg DL. Estimation of age at death in human males from quantitative histology of bone fragments. American Journal of Physical Anthropology, 1970, 33(3):373-381

[27] Currey JD. Some effects of ageing in human Haversian systems. Journal of Anatomy, 1964, 98(Pt 1):69-75

[28] Walker RA. Assessments of human cortical bone dynamics and skeletal age at death from femoral cortical histology. Phdthesis, Ohio: Kent State University, 1990

[29] Thompson DD. The core technique in the determination of age at death in skeletons. Journal of Forensic Science, 1979, 24(4):902-915

[30] Thompson DD. Age changes in bone mineralization, cortical thickness, and haversian canal area. Calcified Tissue International, 1980, 31(1):5-11

[31] Thompson DD, Gunness-Hey M. Bone mineral-osteon analysis of Yupik-inupiaq skeletons. American Journal of Physical Anthropology, 1981, 55(1):1-7

[32] Cosgriff-Hernandez M.T. Histomorphometric estimation of age at death using the femoral cortex: A modification of established methods. Phd thesis, Columbus: Ohio State University, 2012

[33] Stout SD. The use of bone histomorphometry in skeletal identification: The case of Francisco Pizarro. Journal of Forensic Science, 1986, 31(1):296-300

[34] Samson C, Branigan K.A new method of estimating age at death from fragmentary and weathered bone. In A. Bodington, A. N. Garland, \& R. C. Janaway (Eds.), Death decay and reconstruction approaches to archaeology and forensic science.England: Manchester University Press, 1987, pp. 101-108

[35]Ericksen MF. Histologic estimation of age at death using the anterior cortex of the femur. American Journal of Physical Anthropology, 1991, 84(2):171-179

[36] Stout SD, Paine RR. Histological age estimation using rib and clavicle. American Journal of Physical Anthropology, 1992, 87(1):111-115

[37] Aiello LC, Molleson T. Are microscopic ageing techniques more accurate than macroscopic ageing techniques? Journal of Archaeological Science, 1993, 20(6):689-704 
[38] Yoshino M, Imaizumi K, Miyasaka S, Seta S. Histological estimation of age at death using microradiographs of humeral compact bone. Forensic Science International, 1994, 64(2-3):191-198

[39] Bertelsen PK, Clement JG, Thomas CD. A morphometric study of the cortex of the human femur from early childhood to advanced old age. Forensic Science International, 1995, 74(1):63-77

[40]Watanabe Y, Konishi M, Shimada M, Ohara H, Iwamoto S. Estimation of age from the femur of Japanese cadavers. Forensic Science International, 1998, 98(1):55-65

[41]Thomas CD, Stein MS, Feik SA, Wark JD, Clement JG. Determination of age at death using combined morphology and histology of the femur. Journal of Anatomy, 2000, 196(3):463-471

[42]Bell KL, Loveridge N, Reeve J, Thomas CD, Feik SA, Clement JG. Super-osteons (remodeling clusters) in the cortex of the femoral shaft: Influence of age and gender. The Anatomical Record, 2001, 264(4):378-386

[43]Cho H, Stout SD, Madsen RW, Streeter MA. Population-specific histological age-estimating method: A model for known African-American and European-American skeletal remains. Journal of Forensic Science, 2002, 47(1):12-18

[44]Thomas CD, Feik SA, Clement JG. Regional variation of intracortical porosity in the midshaft of the human femur: Age and sex differences. Journal of Anatomy, 2005, 206(2):115-125

[45]Maat GJ, Maes A, Aarents M, Nagelkerke NJ. Histological age prediction from the femur in a contemporary Dutch sample. Journal of Forensic Sciences, 2006, 51(2):230-237

[46]Chan AH, Crowder CM, Rogers TL. Variation in cortical bone histology within the human femur and its impact on estimating age at death. American Journal of Physical Anthropology, 2007, 132(1):80-88

[47]Britz HM, Thomas CD, Clement JG, Cooper DM. The relation of femoral osteon geometry to age, sex, height and weight. Bone, 2009, 45(1):77-83

[48]Nor FM, Pastor RF, Schutkowski H. Age at death estimation from bone histology in Malaysian males. Medicine, Science and the Law, 2014, 54(4):203-208 
[49]Abdullah H, Nor FM, Jamil MA. Human bone histomorphological pattern differences between genders: A review. InInternational Conference for Innovation in Biomedical Engineering and Life Sciences, 2015, pp. 183-187

[50]Khan I, Jamil MM, Ibrahim TN, Nor FM. Analysis of age-related changes in Haversian canal using image processing techniques. In6th IEEE International Conference onControl System, Computing and Engineering, 2016, pp. 169-172

[51]Khan I, Jamil MM, Ibrahim TN, Nor FM. Automated human age estimation at death via bone microstructures. In6th IEEE International Conference onControl System, Computing and Engineering, 2016, pp. 580-583

\section{How to cite this article:}

Khan I, Jamil M M A, Nor F M. Evaluation and reliability of bone histological age estimation methods. J. Fundam. Appl. Sci., 2017, 9(4S), 663-680. 